\title{
Antonio Joaquim Ribas *. (O Conselheiro Ribas)
}

\author{
Carlos S. de Barros Junior \\ Docente de Direito Administrativo na Fa. \\ culdade de Direito da Universidade de \\ São Paulo.
}

\begin{abstract}
"Tout historien devrait être jurisconsulte, tout jurisconsulte devrait être historien."

Quão bem avisado o asserto que assim põe no limiar do seu clássico livro sobre a Historia da Legislação Romana o eminente Ortolan.

E no prefácio, lá o reitera Labbé: "Les ètudes historiques et les ètudes juridiques se complètent; elles doivent se prêter un mutuel secours."
\end{abstract}

De Ruy, segundo me parece, perdida em alguma passagem desse mundo que é a sua obra, a asserção, ao seu tempo com foros ainda de maior acerto, de que o conhecimento do Direito Civil é a pedra-de-toque do jurista.

A história do direito privado, a história em si, dos costumes e das instituições, no que uma e outra refletem a evolução da cultura, o progresso e o aperfeiçoamento humano, permitem melhor apreender e compreender o direito público.

Antonio Joaquim Ribas, o Conselheiro Ribas, patrono da cadeira n. 39 desta Academia, foi historiador, civilista notável e publicista de muitos méritos.

O Direito é projeção do passado na formação do futuro. E história e cultura.

* Elogio do patrono da cadeira n..$^{0} 39$, da Academia Paulista de Direito, pelo Acadêmico-titular Carlos S. de Barros Júnior, proferido na sala "João Arruda", da Faculdade de Direito da USP. 
A história é contemporânea da vida e da melhoria do homem. Só inserido em tal contexto, ele bem se divisa, em sua caminhada de eternidade. E o Direito há que ser adequado a cada um dos estágios dessa evolução, deve por-se em contato com as exigências da vida e da realidade social e política. Donde o mencionar-se frequentemente a historicidade do Direito.

Completam-se História e Direito.

Ribas foi lente de história universal.

Substituiu em 1841, no Curso Anexo, o estranho e misterioso Júlio Frank.

Assinala-se mesmo, como acontecimento marcante de sua vida, o seu encontro com esse personagem. Sob sua influência, teria formado a sua cultura humanista, aprendendo, segundo refere Vampré, "filosofia, história universal, literatura, latim, grego, francês, inglês e alemão", o que lhe dava, ao tempo de seu ingresso na Academia de Direito de São Paulo, preparo superior ao da maioria dos estudantes de sua idade.

Colabora com Júlio Frank na redação de uma "História Universal". Jorge Americano, que lhe traça a biografia, escreve a propósito: "trabalharam juntos na obra, parece fácil reconhecer o estilo do primeiro na obra do segundo"

Tem Ribas, assim, desde moço, o espírito voltado ao conhecimento dos costumes e instituições dos povos e civilizações no seu evolver

Como mestre, fêz da história um estudo verdadeiramente científico, observa Almeida Nogueira. E por ela, na reflexão diuturna dos acontecimentos e das transformações sociais, chega à melhor compreensão do direito privado e do direito público.

A preocupação com os estudos históricos e também geográficos aliás ciências que se interligam - conserva-os Ribas por todo o decorrer de sua vida e torna-se, em 1861, sócio do Instituto Histórico. Refere Jorge Americano uma "História dos Paulistas", inédita, de sua autoria, trabalho também mencionado em publicação editada em 1935, pelo "Jornal do Brasil", sob a epígrafe "Galeria Nacional - Vultos Proeminentes da História Brasileira"

Contemporaneamente a sua nomeação para professor do Curso Anexo, Ribas defende tese e recebe o grau de doutor.

Em 1854, com a reforma dos cursos jurídicos, é nomeado lente substituto e entra a lecionar na Faculdade. 
Regeu várias cadeiras — ensinou economia política, direito eclesiástico, direito público, direito administrativo.

Não há substituir as palavras com que Almeida Nogueira escreve sobre as suas virtudes de professor: "Ninguém sobre ele se avantajou no exercício do alto magistério. Era um lente completo. Metódico e claro na exposição, profundo nas investigações, criterioso nos conceitos, lógico e agudo na crítica, invencível na argumentação. E todas estas vantagens realçadas, quanto à forma, por palavra fluente e elegante, diç̧ão nítida e voz de agradável timbre."

Lembre-se o relato do antigo Ministro do Supremo Tribunal Federal, Francisco de Paula Ferreira de Rezende, em seu curioso livro de memórias "Minhas Recordações", sobre o convite feito a Ribas para reger a cadeira de Direito Administrativo.

Pertenceu Ferreira de Rezende à turma que primeiro estudou a matéria em nossa Faculdade. Decreto de 1851 havia autorizado a criação da cadeira, a qual veio a ser instalada de 1853 a 1854 e colocada no $5 .^{\circ}$ ano do curso.

Esclarece Ferreira de Rezende que o ensino da disciplina se tornou efetivo em 1855.

Era matéria inteiramente nova. Atente-se que, até mesmo na França, era recente a criação da cadeira.

E daí, conta Ferreira de Rezende que, por essa circunstância, teria o governo escolhido de propósito para ela um professor de reconhecida inteligência, dos mais antigos e que era também antigo e dos mais provectos parlamentares.

Ouçamos o memorialista, em seu sabor estilístico peculiar: "O escolhido foi. o doutor e hoje senador José Inácio Silveira da Mota. Tendo, sem que eu já me recorde bem o por que, o apelido de Mota Luzo, o Dr. Silveira da Mota era homem calvo; desembaraçado no andar; cujo rosto, se bem me recordo, era bexigoso; e cuja cor era de um vermelho tão carregado, que se poderia o tomar como um homem ameaçado de morféia. Como lente, falava com extrema facilidade e muito mais talvez do que ainda hoje, não cessava a todo momento do pronunciar esta frase - verbi gratia - que havia nele já se tornado uma espécie de cacoete. Tendo dado o seu cavaco no dia da abertura da academia o Dr. Silveira da Mota durante alguns dias não tornou a comparecer à aula. Passados, entretanto, alguns dias, ele de novo alí se apre- 
sentou: subiu para a cadeira; e depois de nos haver dito, que por maiores que tivessem sido os seus esforços, não the havia sido possível descobrir um único livro que nos pudesse servir de compêndio, mete em seguida a mão no bolso de sua casaca: dele tira um número do Jornal do Comércio; e nos declara que seria o Jornal do Comércio ou o orçamento do império que nele se achava, o que nos teria de servir de compêndio. Nós não pudemos, à vista de uma semelhante declaração, deixar de arregalar um pouco os olhos, e de nos olharmos uns para os outros. E como não era possível de modo algum compreender como o Jornal do Comércio ou como o orçamento do império pudesse ser jamais um compêndio e quanto mais um bom compêndio, de ciência alguma; o que se nos afigurou como muito mais certo, é que bem pouco teriamos afinal de ficar sabendo do direito administrativo. Aquele ano, porém, não sei se por alguma epidemia ou por que outra qualidade de motivo, parece que foi um dos anos de maior contradança parlamentar; porque tendo nós tido como lentes de economia política aos Drs. Carneiro de Campos, Carrão e Martim Francisco, que eram todos deputados ou suplentes de deputados; apenas um deles entrava para tomar conta da cadeira; daí a pouco era chamado, ou estava marchando para a Côrte; de sorte que, se durante todo o ano, tivemos cinquenta lições desta matéria, seria talvez o mais. Ora, apenas o Dr. Mota deu a primeira ou segunda lição do Jornal do Comércio, foi igualmente como os outros, chamado para a Corte; e para substituí-lo foi nomeado o Dr. Furtado. Este nem sequer compareceu à aula. Mas depois de ter-se feito esperar durante alguns dias, acabou por escusar-se; e para substituí-lo foi afinal designado o Dr. Ribas. Gozando de uma fama de muito grande talento, ninguém acreditava que ele pudesse recusar um tal encargo. Mas dois, três dias, já haviam passado sem que o homem nos aparecesse na aula e nós já começávamos a chasquear daquela tão grande inteligência engarrafada, quando no quarto dia ele se nos apresenta; e nos diz que debalde havia procurado um livro que nos pudesse servir de compêndio; mas que não sendo possível que por esse motivo se deixasse de estudar a matéria; ele se havia lembrado de organizar uns apontamentos que ele nos daria ou que ele nos iria dando para copiar; e que seriam esses apontamentos os que teriam de nos servir de compêndio Então tirou do bolso os tais apontamentos; e desde então no-los principia a ler e ao mesmo tempo a no-los explicar. Quando a aula terminou, o homem estava conhecido 
e soberamente julgado. Os seus apontamentos eram um verdadeiro primor didático onde não se sabia o que mais se deveria admirar, se a profundeza, se o método ou se a clareza.

Foram, por certo, os apontamentos de aula da referência de Ferreira Rezende, que ao depois se converterem no "Direito Administrativo Brasileiro", obra premiada e aprovada pela Revolução Imperial de 9 de fevereiro de 1861, adotada para servir como compêndio nas Faculdades de Direito do Recife e São Paulo. Foi editada no Rio de Janeiro, em 1866.

Mas só em 1855 e parte do ano seguinte regeu Ribas a Cadeira. Não se torna professor dessa matéria. Em meados de 1856 é nomeado para a cadeira de Direito Administrativo Francisco Maria de Souza Furtado de Mendonça, por ter Silveira da Mota requerido a sua jubilação.

Ribas, todavia, é lente insigne e de prestígio em outros ramos jurídicos que não só em Direito Administrativo. $\mathrm{E}$ esse prestígio - dí-lo Almeida Nogueira - sempre ele o conservou, aumentando-o mesmo consecutivamente em todas as cadeiras que veio a reger, enquanto lente substituto, até que se tornou, quando catedrático de Direito Civil, em 2 de abril de 1860, um dos mais notáveis jurisconsultos pátrios e astro de primeira grandeza na Congregação da Faculdade de São Paulo.

E como civilista que Ribas especialmente se projeta. Nesse campo, é das maiores expressões do direito brasileiro.

Significativo desta projeção é na tradição saborosa da Academia a conta em que o tinha o professor Vicente Mamede. Exigia que os alunos, como ele, soubessem o Ribas de cor. E advertia-os que ao explanar as suas lições - o que fazia também repetindo sem tirar nem por os seus autores prediletos — se era Lafayette que expunha, dizia o Con. selheiro Lafayette, porque quando mencionava apenas "O Conselheiro", referia-se a Ribas.

Alude a isto Armando Prado, em passagem de pequeno mas curioso livro que intitulou "Sem Rei Nem Roque", mas inverte o fato, certamente por equívoco. Escreve: "Quando falava no Conselheiro, sem mais nada aludia a Lafayette; quando se agarrava a Ribas, dizia sempre, sem probabilidade de engano - o Conselheiro Ribas". A versão certa, po rém, parece ser a de Jorge Americano e que temos ouvido sempre repetida na Academia — "Mamede, aliás prevenia sempre no inicio do 
curso - e isto é conhecido de muita gente: Quando eu quero falar no Conselheiro Lafayette, eu digo Conselheiro Lafayette, porque quando eu disser "o Conselheiro é o Conselheiro Ribas"

$\mathrm{E}$ os tópicos assim memorizados pelo Mamede eram passagens do "Curso de Direito Civil" do Conselheiro.

Do Direito Civil, Ribas é sabedor profundo. Revela-o em toda a explanação do seu referido "Curso", cuja primeira edição data de 1866 , e que foi reeditado em 1880 e 1905.

Ribas é um humanista e jurista. E, como vimos, excelente professor.

"Estudara bem filosofia e melhor ainda história universal e literatura. Também aprendera latim e grego, além de várias linguas vivas, como o francês, o inglês e o alemão", informa Almeida Nogueira, do mesmo passo que se refere a Ribas como lente completo.

O "Curso de Direito Civil Brasileiro" assim o aprecia Candido de Oliveira, em "Notas preambulares" à $3 .^{\text {a }}$ edição: "Rara clarividência jurídica; amplo conhecimento da História e das fontes, vastíssima erudição, ao lado da vernaculidade da oração e da elegância do estilo - são os predicados que, prima facie, asseguram ao livro de Ribas um lugar de honra na nossa tão minguada bibliografia jurídica."

Donde, por sua vez, a asseveração de Irineu Strenger, em estudo sobre a contribuição de Ribas à dogmática do Direito Civil Brasileiro de que foi ele o primero a realizar, no Brasil, a sistematização do Direito Civil.

No prefácio à $2 .^{\text {a }}$ edição do "Curso", escrevia Ribas, em 1880 , "julgar haver completado a teoria fundamental e geral do Direito Civil pátrio, teoria que contem em si - enunciava - a chave da solução de todos os problemas jurídicos, que na prática se oferecem, por mais intrincados e árduos que sejam."

E, realmente o fez - afirma Irineu Strenger, na monografia referida - compilando de maneira harmônica e simétrica os temas do Direito Civil aproveitando a profusa legislação que examinou e interpretou metodicamente, reconhecendo nos conceitos da parte geral não somente instrumentos para ordenar e expor o fenômeno jurídico, como na realidade estabeleceu princípios com um conteúdo próprio, substancial, de caráter superior." 
Ribas faz refletir na sua obra as mais importantes correntes do pensamento jurídico do século XIX. Conhecedor da lingua, abebera-se das mais estimulantes fontes, notadamente da doutrina pandectista alemã.

Donde o seu apreço à Parte Geral do Direito Civil, propugnada sob influxo dessa corrente doutrinária .

Sofreu a influência das escolas filosófico-jurídicas de sua época, sem ilhar-se num ou noutro sistema, atenta a lição de Cogliolo em sua "Filosofia do Direito Privado", onde escreve: "o racionalismo passado, que resumia o ser no pensar, fazia todas as nossas instituições derivadas da razão; a Escola Histórica se lhe opôs vigorosamente, derivando-as da consciência popular, mas exagerava esse conceito por querer naturalizá-1o demais e considerar sempre o direito como um produto espontâneo e imediato da vida de uma nação. Mas a observação dos fatos, isenta de preconceitos, indica que em ambos os sistemas há uma parte de verdade: a consciência popular com efeito faz sentir as necessidades e pressentir sua satisfação possível, mas a norma, que se destina a esse fim, é pensada e formulada pela mente humana. No Direito entram, portanto, dois elementos de igual importância, isto é, - um natural e outro lógico - a sociedade e o raciocínio - as necessidades da vida e a força - intelectual do homem" (tradução de Irineu Strenger)

Das correntes historicista, pandectista e dos princípios da doutrina da exegese compõe Ribas as suas motivações teóricas, os preceitos que vão embasar a sua contribuição doutrinária a uma visão sistemática do Direito Civil pátrio.

Forrado de tais conhecimentos, empreende, no seu "Curso de Direiio Civil", a sistematização do direito civil nosso, fixando-lhe a teoria fundamental e geral.

Acompanhemo-lo na exposição de seus princípios doutrinários:

"O direito manifesta-se na história como uma força viva, que germina no seio dos povos desde a sua idade primitiva, que se desenvolve e transforma no tempo e no espaço segundo uma lei de lógicas evoluções. Mas, além desta manifestação histórica, ele revela-se à nossa consciência como afirmação múltipla, já da razão espontânea e refletida já no sentimento e do dogmatismo religioso. Com efeito, em presença dos atos humanos, aparece espontaneamente na razão, a idéia do direito, como um princípio qualificador desses atos e sentimos a necessidade irresistível de julgá-los, segundo este princípio - como justos ou injustos" 
Vale a pena transcrever ainda estas asserções, que revelam aspectos fundamentais de sua concepção do mundo jurídico: " $\mathrm{Da}$ ordem que reina no mundo físico, deduzimos, como consequência lógica, a do mundo moral; não é na verdade possível, que a parte mais elevada e perfeita da criação esteja privada dela. O princípio criador não pode deixar de presidir à toda a sua obra, e a anarquia ainda é mais difícil de conceber-se no mundo da liberdade, do que no da fatalidade. Como, porém se concilia o princípio de liberdade com o de ordem providencial? E este um dos mais árduos problemas de que a filosofia, a teologia e a história têm tratado, mas cuja discussão fora inteiramente estranha ao nosso assunto. Assás é lembrarmos que, se a consciência nos dá a profunda afirmação da lei divina da ordem moral e jurídica, dá-nos igualmente a inabalável afirmação de nossa liberdade, que se confunde com a nossa própria atividade e existência; de sorte que o homem tem ao mesmo tempo consciência da sua existência e da sua liberdade. A ordem providencial se realiza, no mundo moral, por intermédio da liberdade. $O$ homem a conhece, e se lhe submete voluntariamente, cooperando assim consciensiosa e livremente para a realização do plano divino: esta é a sua glória e o seu título de superioridade em toda a criação. No mundo físico, pelo contrário, ela se realiza com o caráter de cega e irresistível fatalidade, o mérito e o demérito aí não são possíveis. Este princípio de ordem, que compreende toda a vida da humanidade, todas as múltiplas relaçóes das frações e individualidades que a compõem, é a noção fundamental da lei moral e jurídica. O direito, porém, não se manifesta somente ao homem por meio da razão no modo espontâneo e refletido de sua atividade; ele se revela também pela sensibilidade hiperfísica, posto que não de modo claro e preciso. Com efeito, os atos conformes à liei moral e jurídica, produzem em nós um sentimento agradável, enquanto os atos contrários a ela provocam o sentimento oposto. O homem justo desperta a simpatia ou uma espécie de atração sentimental, enquanto o perverso gera a antipatia e a repulsão. A aprovação ou condenação, que de nossos próprios atos faz a consciência, se reflete na sensibilidade em emoções de prazer ou de dor, segundo esses atos são ou não conformes à lei proclamada pela razão."

Eis como o jurisconsulto remontava às raizes de suas convicções. 
Quanto ao seu historicismo, além do que nas passagens referidas se estadeia, revela-se igualmente quando escreve: "O jurisconsulto só pode ter consciência que possui a inteligência completa de uma instituição jurídica, que a assimilou verdadeiramente, quando, remontando-se à sua primitiva origem, a houver acompanhado através de todas as formas históricas, de que ela se revestiu, até chegar ao estado atual, penetrando ao mesmo tempo nas razões de suas sucessivas modificações."

Melhor precisando a sua concepção doutrinária, eis outro passo do seu "Curso": "Estudando a natureza individual e social do homem e as condições precisas para o preenchimento de seus fins, pode a razão de per si formular um sistema de Direito; é este o direito racional. O direito positivo pelo contrário não o descobrimos pelo simples exercício da razão, e sim o recebemos do testemunho humano - o assentimento universal, ou a promulgação oficial." $\mathrm{E}$, referindo-se às correntes do pensamento jurídico então atuantes e que eram, em grande parte, novidades em nossa ao tempo incipiente jurisprudência, prosseguia: "Não queremos agora reproduzir a crítica desses sistemas, que com tanta habilidade tem sido feita por outros; faremos, porém, algumas rápidas considerações sobre o princípio fundamental de escola histórica, por ser a sua doutrina ainda pouco conhecida entre nós, e porque vindo este princípio de envolta com grandes e importantes verdades, tanto mais facilmente se pode insinuar como verdadeiro. Savigny sustenta que o direito vive primitivamente na consciência comum de cada povo; não porque os indivíduos que o compõem tenham contribuido arbitrariamente para a sua formação, mas porque exprime o espírito geral que os anima; que em todos os países, remontando aos monumentos históricos mais antigos, encontra-se sempre o direito como preexistente, e que para melhor excluir toda idéia de acaso ou de arbitrariedade em sua origem, as tradições no-lo mostram por toda parte como emanando de origem divina. Convimos que o direito, como a lingua e os usos de cada povo, seja a expressão do seu espírito geral, ou os traços característicos de sua individualidade; e como está esta sujeita a sucessivas transformações em virtude da lei do progresso - lei divina que preside a toda a criação, não podemos deixar de reconhecer que o direito para espelhar fielmente a vida nacional, há de passar por evoluções lógicas paralelas, regidas pela mesma lei necessária, e igualmente independente do alvedrio humano, 
e por mais razão do acaso. Esta espontaneidade da formação e dos desenvolvimentos do direito obra com toda a sua força e todo o seu elastério nos povos primitivos, porque aí há mais coesão e solidariedade nos indivíduos, mais unidade na vida nacional. Quando, porém, os indivíduos começam a destacar-se em desenvolvimentos parciais e desiguais, a consciência comum do povo começa a obscurecer-se, e como que o direito se vai nela apagando e confundindo-se"

E aduz: "Cumpre, porém, não esquecer que a mesma escola histórica reconhece na natureza do direito dois elementos essenciais - um individual e exclusivo a cada povo, outro geral e comum a toda a humanidade. Se alguns jurisconsultos se têm transviado por atenderem somente ao elemento geral, por considerarem o direito como idéia absoluta sem se importarem com as suas manifestações na vida real e social, outros têm se transviado em sentido oposto, por só atenderem ao elemento individual e só verem no direito a realidade objetiva, as fórmulas transitórias. A verdade está no meio têrmo: o direito não é por certo uma criação da vontade geral, ou da lei, como ensinaram Rousseau e Bentham; nem uma espécie de vegetação que brota espontâneamente e inconsciente no meio da Sociedade, que instintivamente se modifica e se transforma nos costumes nacionais. A humanidade acha na razão o direito como noção fundamental, que esclarece os labirintos da vida, que coordena e sustenta a sociedade; como tipo inalterável, idéia hiperhumana, com a qual ela compara os atos de todos os agentes livres, os costumes nacionais, as leis solenemente decretadas, os julga e os condena ou absolve. É verdade que este ideal não é um código desenvolvido, ou complexo de instituições, que todos os povos em todos os tempos possam executar do mesmo modo. Não por certo; é um princípio geral que todos devem realizar historicamente isto é, cada um segundo as suas condições próprias, e o grau de desenvolvimento a que tiver atingido nas várias esferas de sua atividade. Os progressos do direito consistem, pois," na lenta atenuação do elemento individual, na sua progressiva homogenização, na sua perene tendência à fusão do elemento geral, sem que, porém, jamais se extingam completamente os caracteres e a energia da vida individual-nacional. É nesse sentido que pode intervir, eficaz e beneficamente, a vontade ilustrada do legislador. Ele não pode por certo impor arbitrariamente um sistema de instituições, forjado em sua fantasia; mas pode remover os embaraços que se opõem às evoluções naturais e 
progressivas do direito, proclamando, como caducas, as formas que de fato houverem caducado, e sancionando com o reconhecimento e a força social as novas formas que logicamente daquelas se houverem desenvolvido, segundo as condições gerais de cada período histórico. O direito racional é o desenvolvimento da noção geral e fundamental do direito, tanto quanto deve ele ter lugar sem degenerar em casuísmo, ou sem invadir as raias do elemento individual. Para este fim deve-se estudar a natureza individual e social do homem, as necessidades e recursos, ou as condições gerais, que todos são chamados a preencher, afim de que possam realizar o fim de sua criação".

Tendo em consideração estas reflexões de Ribas, comenta Irineu Strenger, no estudo já referido, em que the examina a obra de civilista: "Estas considerações de Ribas são muito sugestivas e evidenciam com clareza a sua familiarização com a doutrina de Savigny que estudou criticamente fundado nas obras contemporâneas dos pandectistas e nas teorias jusnaturalistas da época"

Com palavras que tomamos de empréstimo a Irineu Strenger podemos tecer o escólio de que muitas passagens da obra de Ribas podíam ser lembradas e reproduzidas para avivar as conexões doutrinárias que cultivava com a Escola da Exegese. Todavia, não seria lícito chamá-lo de representante ortodoxo da exegética, visto que alimenta fundas simpatias pela Escola Histórica e pelas correntes pandectistas alemãs, fazendo uma espécie de caldo de cultura do qual se utilizou com largo proveito para as letras jurídicas nacionais, praticamente construindo os alicerces da Dogmática do Direito Civil.

E um jurisconsulto desse lastro doutrinário que empreende sistematizar o direito civil pátrio e escreve no prefácio da $2 .^{\mathrm{a}}$ edição de seu "Curso", vinda a lume em 1880, como vimos, que a teoria geral e fundamental do Direito Civil contém em si a chave da solução de todos os problemas jurídicos, que na prática se oferecem, por mais intrincados e árduos que sejam. Pois, no Direito Civil, pondera, com verdade que todos aceitam - encontramos princípios sintéticos, que mais ou menos modificados podem-se aplicar a todas as instituições de Direito.

Não só presta assim Ribas fecunda contribuição à sistematização pioneira do nosso Direito Civil, como integra a comissões designadas para estudo dos projetos de Código Civil, no longo período em que, a partir do Império, o escol de nossa inteligência jurídica se dedica ao la- 
bor da codificação civil. Nesse esforço, participa das comissões de revisão dos projetos Teixeira de Freitas e Joaquim Felício dos Santos.

Estamos vendo, com o decorrer desta palestra, que Antonio Joaquim Ribas, o Conselheiro Ribas, é um erudito, um humanista em toda a extensão da palavra. Se não é filósofo, conhece as correntes filosóficas do seu tempo. E está a par das principais escolas que dominam o cenário jurídico dos séculos XVIII e XIX.

De seus conhecimentos, atestados na ampla bibliografia que versa, e sob a influência, como dissemos, do historicismo, da escola da exegese e das correntes pandectistas alemãs, elabora a sua dogmática e o seu sistema. E, no Direito Civil, encontra "os princípios sintéticos, que mais ou menos modificados podem-se aplicar a todas as instituições de Direito"

Ocorre-me indagar, a esta altura, se não teria sido precisamente esta ampla visão dos problemas do direito, o seu conhecimento profundo da teoria fundamental e geral do direito civil, que permitiram a Ribas lecionar com proficiência também o direito público e incumbir-se de fato das primeiras lições de Direito Administrativo ministradas na Academia de São Paulo.

Silveira da Mota, o primeiro lente, vimos que se não saira bem no ensino da nova disciplina, posto que erudito e muito inteligente. Tampouco Furtado de Mendonça.

"Veio por isso Ribas reger a cadeira - escreve Vampré - e o fez com aquele brilho e eloquência, que ainda hoje se divisam nos seus discursos, e em páginas inspiradas, onde o espírito livre das peias do direito positivo, se alça em generalidades e em sínteses fulgurantes"

E Ribas começa a trabalhar nos alicerces do nosso Direito Administrativo, como mais tarde registrará no prefácio do seu livro.

É certamente a sua percepção histórica do Direito e a visão sistemática dos seus instintos fundamentais que lhe fornecem as achegas essenciais às suas primeiras formulações da novel disciplina .

Sabemos que o direito privado precede historicamente o direito público. Ao menos como ciência, e só neste sentido temos que considerar o tema. A principiologia — se assim podemos designar a unidade sistemática de princípios básicos — de um e outro desses ramos do Direito é evidentemeente diversa. 
Não se diz com isto que se trata de campos com separação intransponíveis, estanques, como é óbvio. Mas, antes, de linhas de orientação, que, aliás, já se esboçavam dentro do próprio direito privado. O que se pode asseverar é que as relações típicas de um e outro ramo são, de coordenação no direito privado, de subordinação as do direito público.

Donde a advertência de Basavilbaso: "La diferencia de estrutura que distingue a las normas de derecho publico de las normas de derecho privado permite asseverar que las relaciones del derecho administrativo con las normas del derecho privado - relaciones entre ciencias integradas por normas heterogénas - no puedem ser de subordinación ni dependência, sino de contactos más o menos sucessivos o de continuidad".

Essa visão historicista e de continuidade, de tendência a diversificação - já subjacente em muitas instituições de direito privado - é a posição em que se colocaram os juristas de direito público e, como vimos, informava o espírito de Ribas. Aberto ao progresso das ciências jurídicas, tinha presente as diferenças que deviam surgir, em função das idéias publicisticas que vinham presidir as novas concepções, por exigências do predomínio dos interêsses coletivos sobre os dos particulares.

Ribas é, pela sua erudição e conhecimento dos princípios gerais, pelo hábito de ver em perspectiva ampla os fenômenos jurídicos, o jurista categorizado para por-se na linha da evolução que se processava, do sistema do direito privado para a dogmática do direito administrativo.

Impossível seria também deixar despercebido Ribas processualista e a contribuição que para este ramo do direito carreou. Tanto se destacou neste campo, que foi incumbido pelo Governo Imperial de consolidar as nossas leis de processo civil de então, elaborando trabalho dos mais notáveis, no qual coordenou e comentou a legislação consolidada.

Com esse suporte de doutrina, que as suas obras revelam, empreende Ribas como vimos, ao tempo desajudado de melhores fontes publicistas, a formulação dos primeiros preceitos e noções relativos ao nosso direito administrativo. Não despreza a contribuição estrangeira, mas não perde de vista a necessidade de examiná-la e analisá-la, para aferir de sua aplicabilidade às instituições nossas .

E o faz com êxito. Sua obra, resultado de sua pesquisa e de suas lições, o "Direito Administrativo Brasileiro", editada em 1866, é, como vimos, premiada pelo Governo Imperial e adotada para servir de compêndio nas Faculdades de Direito do Recife e São Paulo. 
Themistocles Cavalcanti, em estudo sobre a evolução do Direito Administrativo no Brasil, assim aprecia o livro de Ribas: "Um dos trabalhos mais perfeitos que se encontram neste setor - examina o período imperial - é o "Direito Administrativo Brasileiro" de Antonio Joaquim Ribas, obra premiada e aprovada pela resolução imperial de 9 de fevereiro de 1861 para uso das aulas das Faculdades de Direito do Recife e de São Paulo. Mas a obra de Ribas está evidentemente incompleta. Basta ler o seu prefácio para verificá-lo. Examinou entretanto, o seu autor os três pontos essenciais do seu esquema: Da ciência do direito administrativo; Da Administração, em sua estrutura, hierarquia e funções; Dos administrados, quanto à sua nacionalidade e condição social. Aqui se encontram os dados essenciais do que Ribas chamou o sentido estrito do Direito Administrativo, isto é, a ciência dos direitos e dos deveres recíprocos da administração e dos administrados. Não deu, porque a vida não lhe concedeu tempo, o desenvolvimento exigido pelo estudo do Direito Administrativo em seu sentido amplo "ciência que ensina a organização administrativa tanto nos seus elementos fundamentais e universais como no seu desenvolvimento prático em um povo dado; o modo pelo qual ela atua sobre a massa geral da população, ou os seus centros parciais, isto é, os serviços incumbidos aos seus agentes gerais ou locais; as formas de que seus atos se revestem, e as modificações jurídicas que em face deles e sob sua influência sofrem os administrados em seus direitos e obrigações. Concepção larga e arejada da disciplina, como se vê, sem sofrer grandes influências e sem sobrecarregar o seu livro com autores estrangeiros, vícios de que se ressente a obra de Uruguay, mais erudita, mais brilhante talvez, porém menos pessoal"

O livro era perfeito para a época. Tanto que algumas matérias ali expostas, como por exemplo a natureza das funções administrativas e as divisões que delas se pode fazer são ainda hoje repetidas por alguns autores. Costumo eu mesmo referí-las, ao ensejo do exame da organização administrativa e das atividades da administração.

Claro está, porém, que o trabalho de Ribas não mais satisfaz às exigências científicas do presente. Fica o seu livro, porém, como dos melhores que sobre o direito administrativo foram publicados ao tempo do Império.

Um civilista, dos mais notáveis da nossa Faculdade de Direito deixaria, assim, no ensino e na doutrina, traço marcante em nosso direito administrativo. 
O jurista não é um heroi ou político, um artista ou guerreiro.

A sua vida se retrai no plano da intimidade, difícil de desvendar. Aliás, a vida do Conselheiro Ribas, é pouco conhecida. Há, como se tem observado, um certo mistério na sua infância, que retorna na velhice. Pouco se sabe de sua vida privada.

Mas, na vida de um jurisconsulto, o que deve ressaltar-se é a sua obra, a sua contribuição para a ciência que escolheu para objeto de seu devotamento.

Foi nesse teor que me aprouve falar do Conselheiro Ribas, ou melhor, d' "O Conselheiro", como prefere a tradição do largo de São Francisco.

Assim há de guardar-se nos fastos desta novel Academia uma vida de tamanha excelsitude - a do patrono da cadeira $n .^{\circ} 39$, ora por mim ocupada por nímia bondade vossa, Senhores Acadêmicos, e generosidade do destino.

Das Academias se diz que precisam mostrar a sua utilidade. Aqui, todos nos encontramos voltados para o labor científico, seduzidos que somos pela importância e venustez do Direito.

Tal a razão por que não me seria lícito encerrar esta palestra, sem um pensamento - o de que a missão que nos congrega há de ser continuamente revivida, pois a luta pela Justiça é sonho que não deve e não pode morrer no coração dos homens. 